Interruptions \& Cognitive Processes in Nursing: Review, Analysis, Recommendations

Patricia R. DeLucia

Tammy E. Ott

Patrick. A. Palmieri

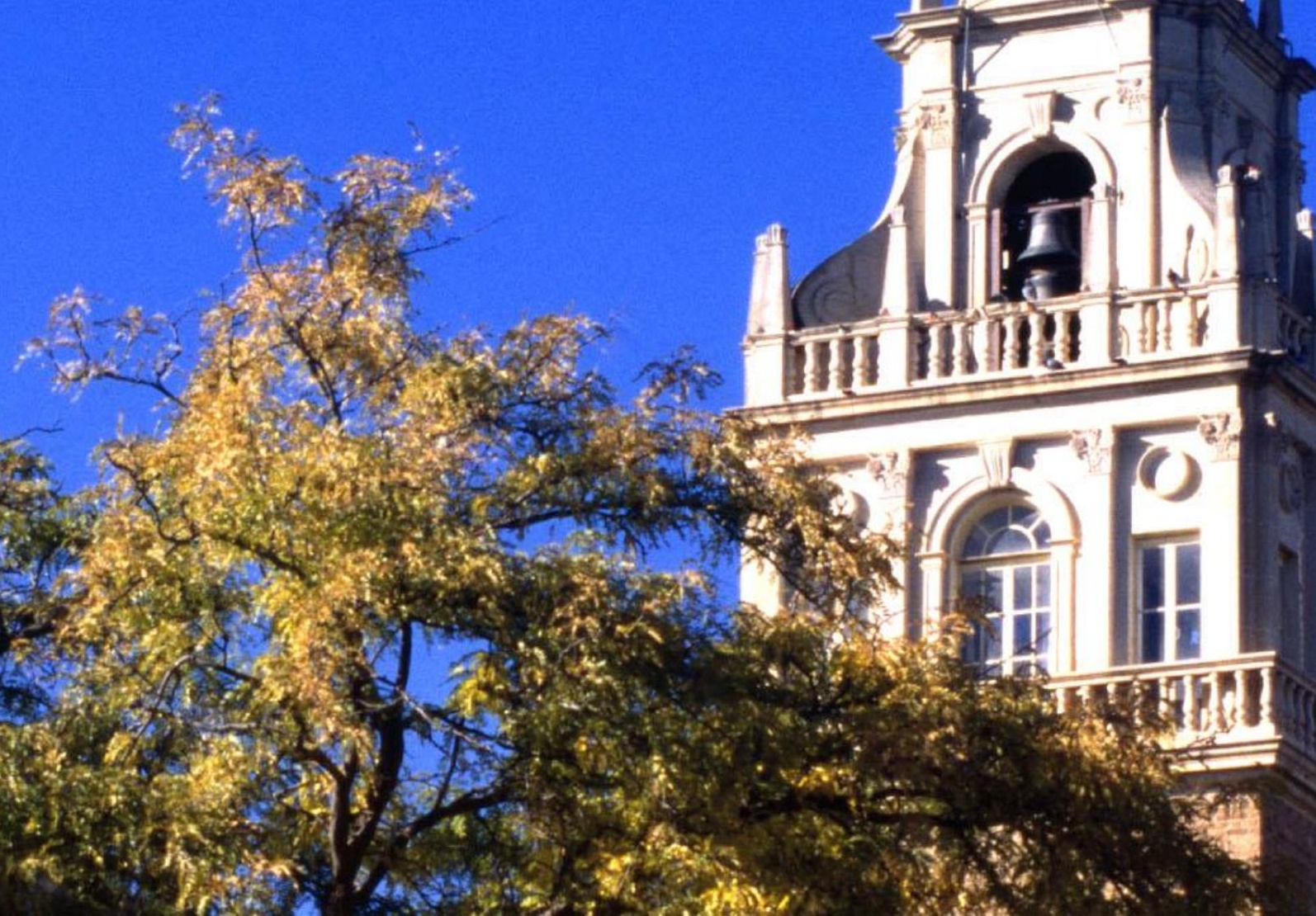


Human Factors and Ergonomics Society

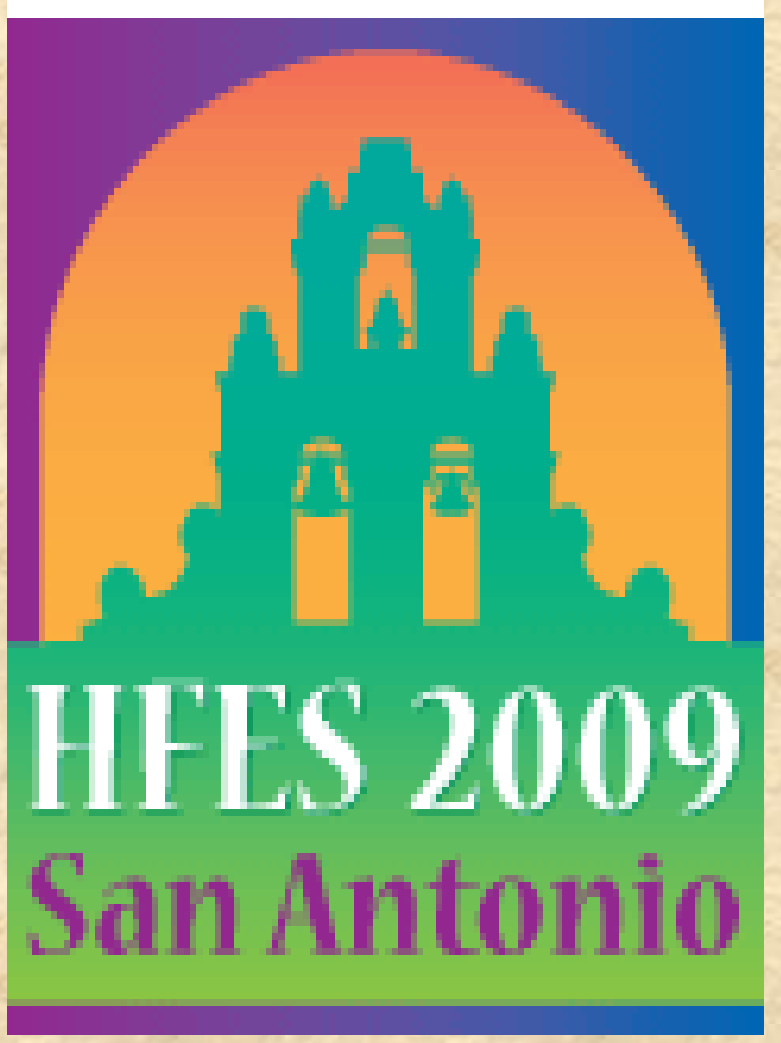

This presentation was prepared by Patricia R. DeLucia, Tammy E. Ott, and Patrick A. Palmieri from the paper, Interruptions and Cognitive Processes in Nursing for the $53^{\text {rd }}$ Annual Meeting of the Human Factors and Ergonomics Society. October 19-23, 2009 


\section{WHY NURSES?}

\section{According to the Institute of Medicine: (Page, 2004)}

* Nurses constitute $54 \%$ of healthcare providers in U.S

* Nurses spend most time with patients compared with other providers

* Quality of nursing care is directly related to patient outcomes

* Design of nurses' work and environment is a key component of patient safety

Enhancements in nursing performance can lead to improvements in patient safety 


\section{COMPRENSIVE REVIEW}

What is known about nursing performance?

DeLucia, P. R., Ott, T. E., \& Palmieri, P. A. (2009). Performance in nursing. In F. T. Durso (Ed.), Reviews of Human Factors and Ergonomics, Vol. 5. Santa Monica: HFES.

Goal: Identify factors that affect the performance of nurses

* Cognitive Factors

* Physical Factors

* Organizational Factors

Today: Interruptions and Cognitive Processes 


\section{INTERRUPTIONS \& MEDICATION ERRORS}

* Medication errors are most common type of health errors (Kohn et al., 2000)

* Analyses of medication errors: (Hicks et al, 2006)

* Data collected between 1999 and 2006

* Interruptions/distractions are a top contributing factor to medication errors in various settings

\begin{tabular}{|l|c|c|c|c|c|}
\hline Contributing Factor & 2001 & 2002 & 2003 & 2004 & 2005 \\
\hline $\begin{array}{l}\text { Distractions (i.e., } \\
\text { interruptions) }\end{array}$ & $47 \%$ & $43 \%$ & $43 \%$ & $47 \%$ & $47 \%$ \\
\hline Workload Increase & $24 \%$ & $22 \%$ & $20 \%$ & $27 \%$ & $26 \%$ \\
\hline Inexperienced staff & $17 \%$ & $18 \%$ & $17 \%$ & $15 \%$ & $19 \%$ \\
\hline
\end{tabular}

Example:

Hicks et al., 2006 


\section{NURSES \& MEDICATION ERRORS}

* Nurses accounted for $86 \%$ of the interceptions of medication errors (Leape et al., 1995)

* Nurses administer medications

* Nurses are the "last defense against medication errors"

(Wakefield, \& Uden-Holman, 2000)
Medication Efrors by Stage (Leape et al., 1995)

$\square$ Dispense $\quad \square$ Transcribe $11 \%$ $12 \%$

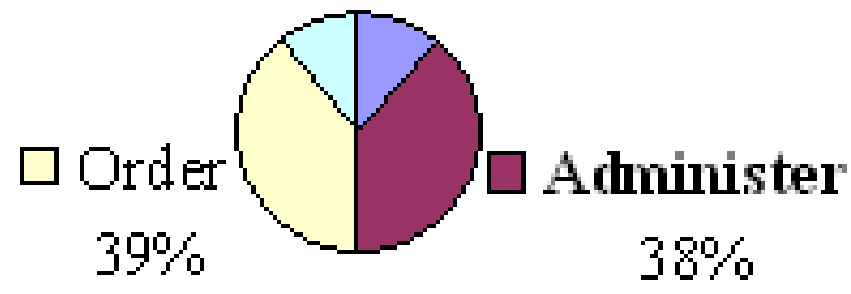




\section{NURSES \& INTERRUPTIONS}

\section{Studied since at least 1959 (smith, 1959)}

* 3.4 - 42 interruptions / hour (Wolf et al., 2006; Woloshynowych et al, 2007)

* Most during direct care (Hedberg \& Larsson, 2004)

* Most while nurse used verbal cognitive resources and relied on memory (Hillel \& Vicente, 2003)

* $2 \mathrm{x}$ as high when medicines given to 1 patient at a time rather than multiple patients (Wolf et al., 2006)

* Often lead to more walking (Gadbois et al., 1992)

‡ Increase cognitive load (Trafton \& Monk, 2008) 


\section{OBSERVATIONS}

\section{Shadowed nurses in $\mathbf{4}$ nursing units:}

* Neonatal intensive care

* Surgical intensive care

* Medical-surgical unit

* Operating room 


\section{OBSERVATIONS - NICU}

\section{Neonatal intensive care (NICU)}

* Open bay (Level 2) with nurses and patients in one large room

* Interruptions came from other nurses, staff, and families

‡ "Quiet room" with 1 or 2 patients

* Interruptions came from phone calls 


\section{OBSERVATIONS - M/S}

\section{Medical-Surgical Floor (M/S)}

* Patient's room

* Interruptions came from healthcare unit clerk to notify of phone calls, some questions

* Hallway or medication room

* Interruptions came from other nurses, staff

* Nurses wore locator tags 


\section{OBSERVATIONS - SICU}

\section{Surgical Intensive Care Unit (SICU)}

* Two patients in adjacent rooms

$\star$ Patients have low mobility

* Interruptions came from other nurses needing help with repositioning of patients. 


\section{OBSERVATIONS - OR}

\section{Operating Room (OR)}

* Nurses monitor and record events

* Interruptions came from phone calls and pages. 


\section{OBSERVATIONS - Global}

\section{ACROSS UNITS}

* Nurses interrupted by patient monitor alarms

* Often the alarm was to notify; not emergent

* Equipment failures, unavailability of equipment led to interruptions in nurse's work

* Led the nurse to interrupt other nurses' work 


\section{NURSES' RESPONSES}

\section{Responses}

* Nurses consider interruptions to be "part of the job"

* Nurses are "used to" interruptions

\section{Strategies}

* Relied on external aids such as scheduling sheet

* Made interrupter wait before responding

* If in middle of procedure, asked another person to answer call

* Did not leave patient for long periods of time 


\section{WHAT WAS LEARNED?}

\section{Major themes}

* Sources of interruptions depended on the nature of the unit

* Sources of interruptions depended on the design of the workspace

* Technologies contributed to interruptions

* Nurses used strategies to manage interruptions 


\section{RECOMMENDATIONS: Literature}

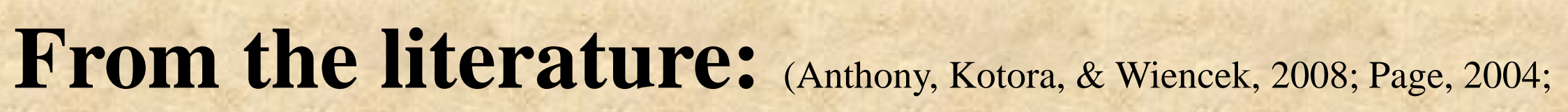

Pape, 2003; Trafton \& Monk, 2008):

* Turn off phones and pages during medication administration

* Close patient's door during direct patient care

* Designate interruption-free times and places

* Limit durations of interruptions

* Use external aids 


\section{RECOMMENDATIONS: Observation 齿离}

\section{Based on our observations:}

$\star$ Consider effects of technology on interruptions before implementation (e.g., locator tag)

* Keep equipment maintained and accessible

* Considering interruptions when designing workspaces

* Allow nurses to manage, control interruptions

* Develop formal strategies and training to help nurses manage interruptions 


\section{COGNITIVE PROCESSES}

\section{There are very few cognitive processes studies in nursing...}

‡ Examples of study findings:

* Nurses' thought processes go beyond the information contained in the medical literature (Crandall \& Getchell-Reiter, 1993)

* Nurses thought processes are more complex than simply applying rules and procedures (Eisenhauer, Hurley, and Dolan, 2007) 


\section{ANALYSIS OF THREE STUDIES}

1) Leape et al., 1995

* Systems analysis of adverse drug events

(interviews following events)

2) Eisenhauer, Hurley, \& Dolan, 2007

* Analysis of nurses' thoughts during medication administration (interviews and think-aloud responses)

3) Stratton et al., 2004

* Nurses' top reasons for medication errors (surveys) 


\section{LEAPE et al., 1995}

\section{Percentage of errors attributed to each category of proximal cause during nurse medication administration}

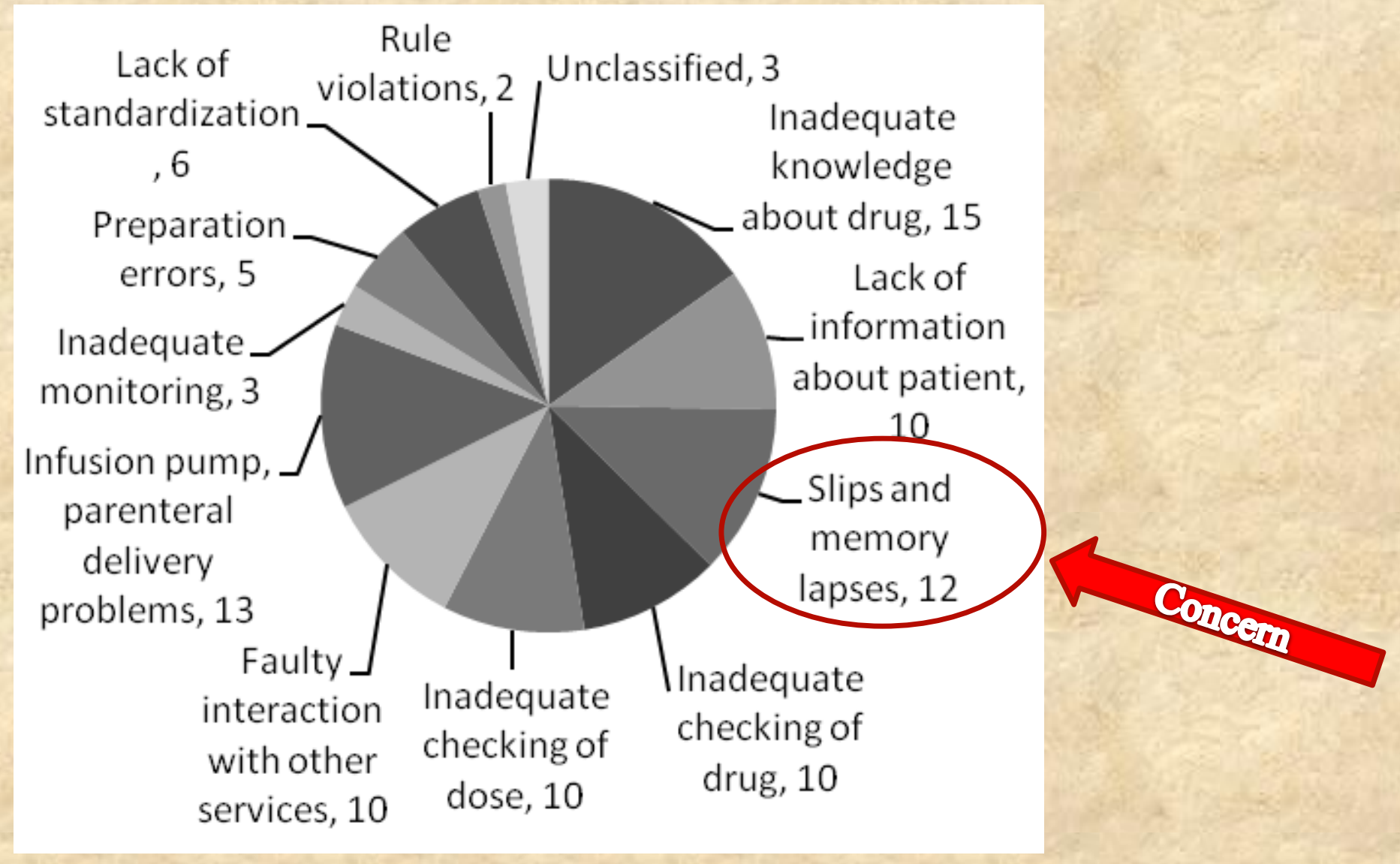




\section{EISENHAUER et al., 2007}

Percentage of times nurses reported thinking about each category during medication administration

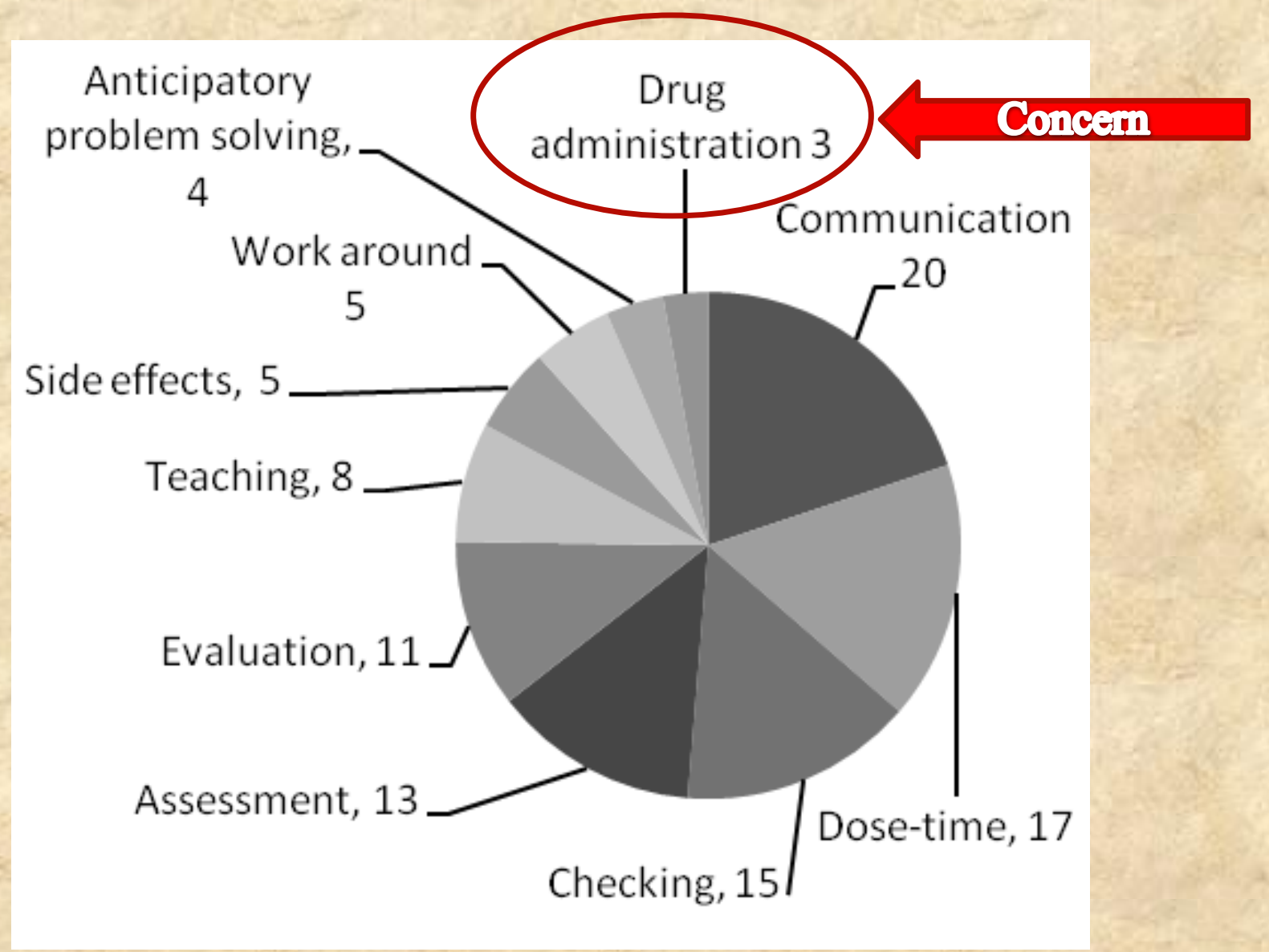




\section{IMPLICATIONS \& RECOMMEDATIONS}

* Slips and lapses occur during skill-based or automatic behaviors (Reason, 1990)

* Medication administration process has become routine or automatic.

* Skill-based errors are often due to a diversion of attention (Wickens, Gordon \& Liu, 1998)

* To reduce skill-based errors, reduce interruptions and distractions 


\section{LEAPE et al., 1995}

\section{Percentage of errors attributed to each category of proximal cause during nurse medication administration}

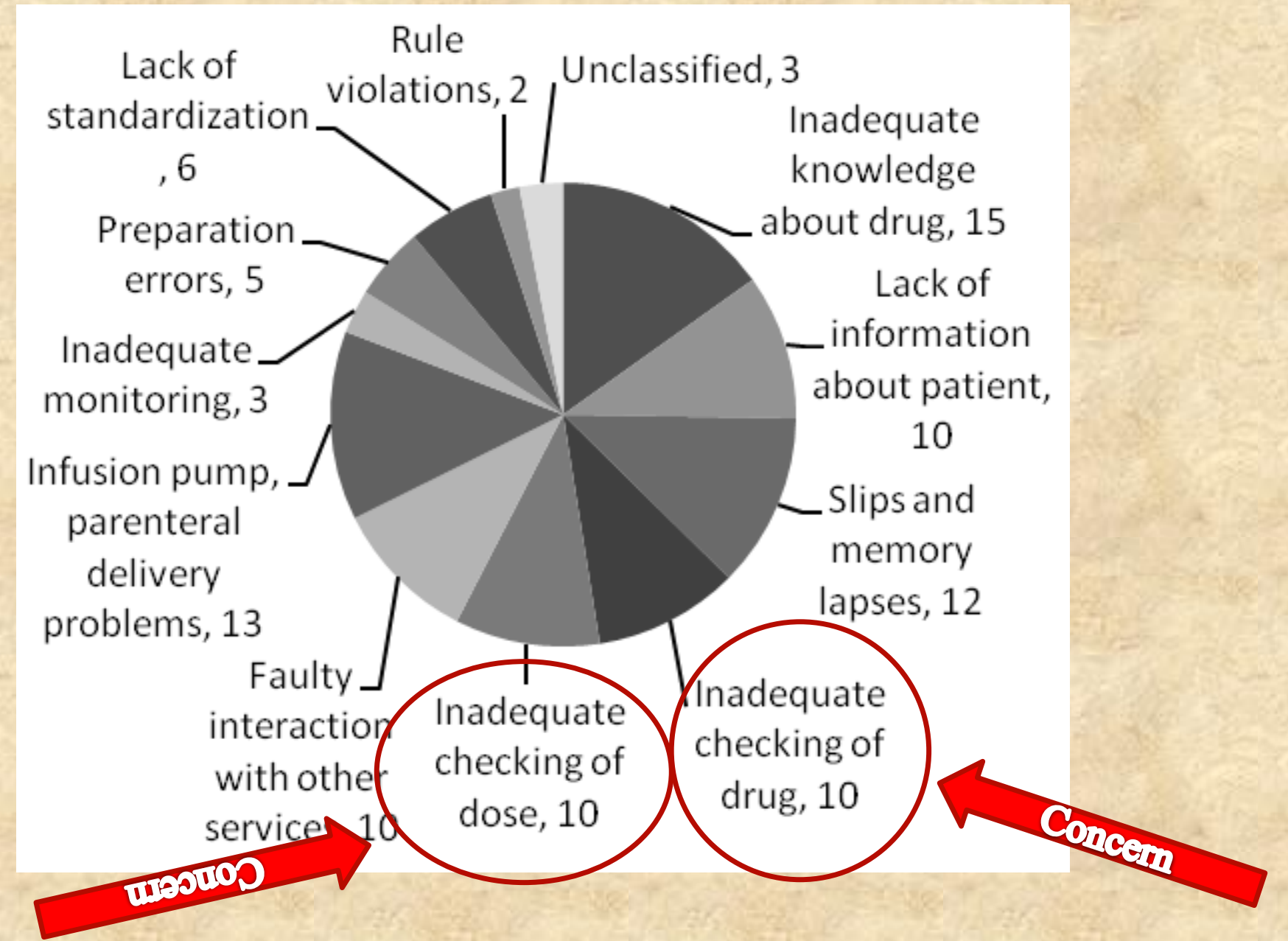




\section{STRATTON et al., 2004}

\section{Percentage of nurse respondents that chose each category as one of the two most important reasons that medication errors occur}

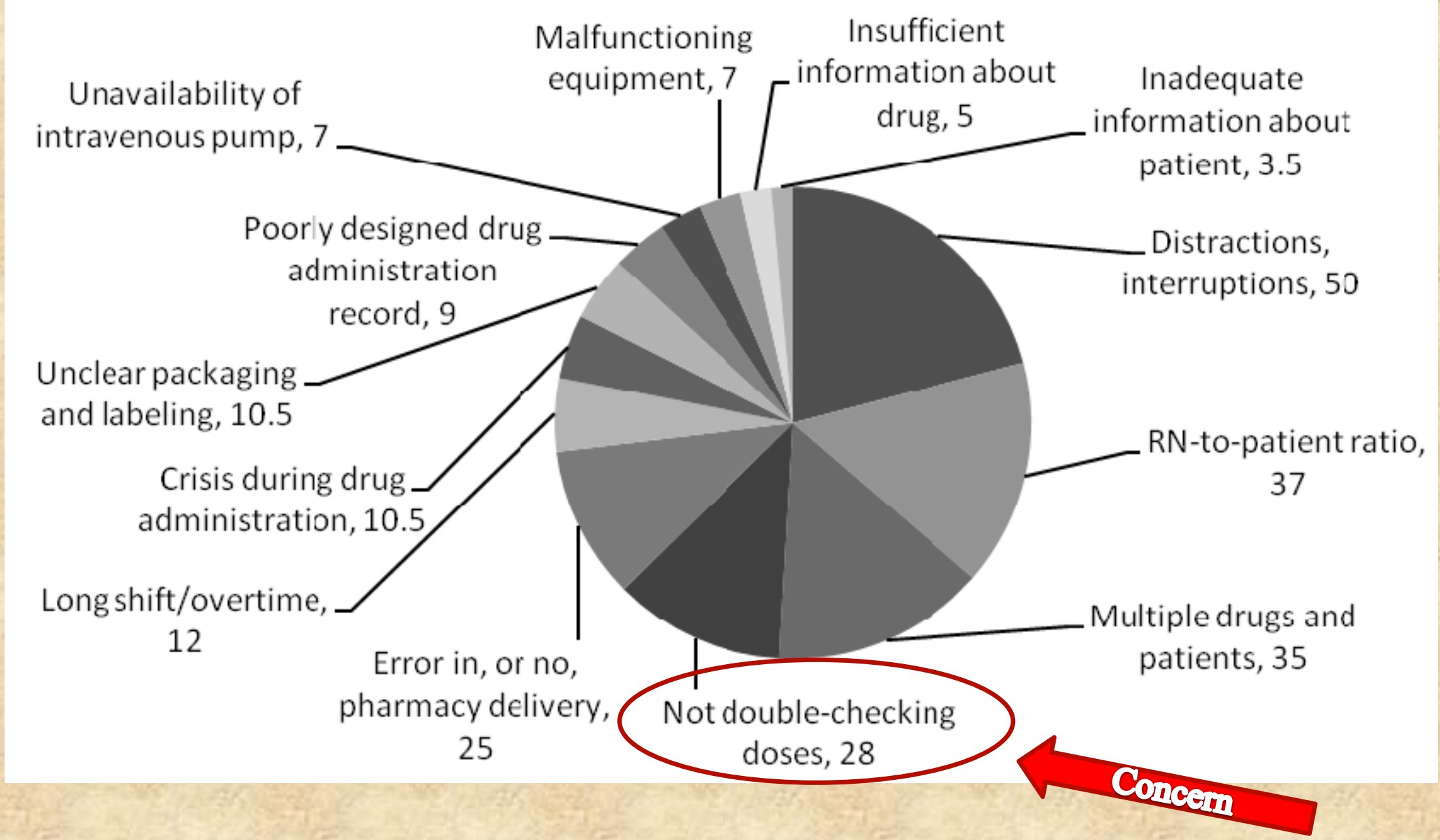




\section{EISENHAUER et al., 2007}

Percentage of times nurses reported thinking about each category during medication administration.

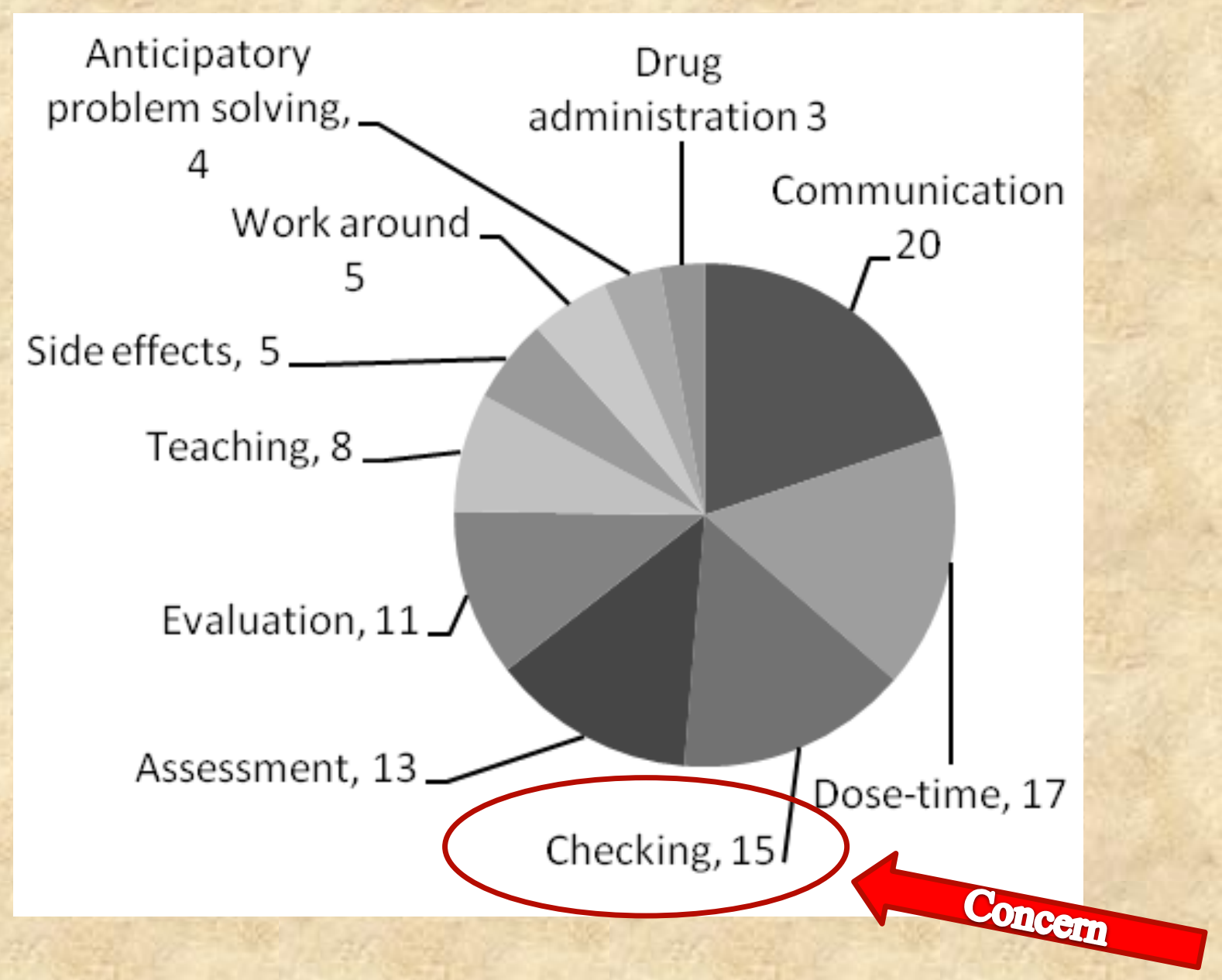




\section{IMPLICATIONS \& RECOMMEDATIONS}

* Nurses think about checking

* Nurses report that not checking is a top reason for medication errors

* ......why do failures to double-check lead to $1 / 5$ of medication administration errors?

* Medication administration process has become routine or automatic

* It is important to reduce interruptions and distractions during medication administration 


\section{LEAPE et al., 1995}

\section{Percentage of errors attributed to each category of proximal cause during nurse medication administration.}

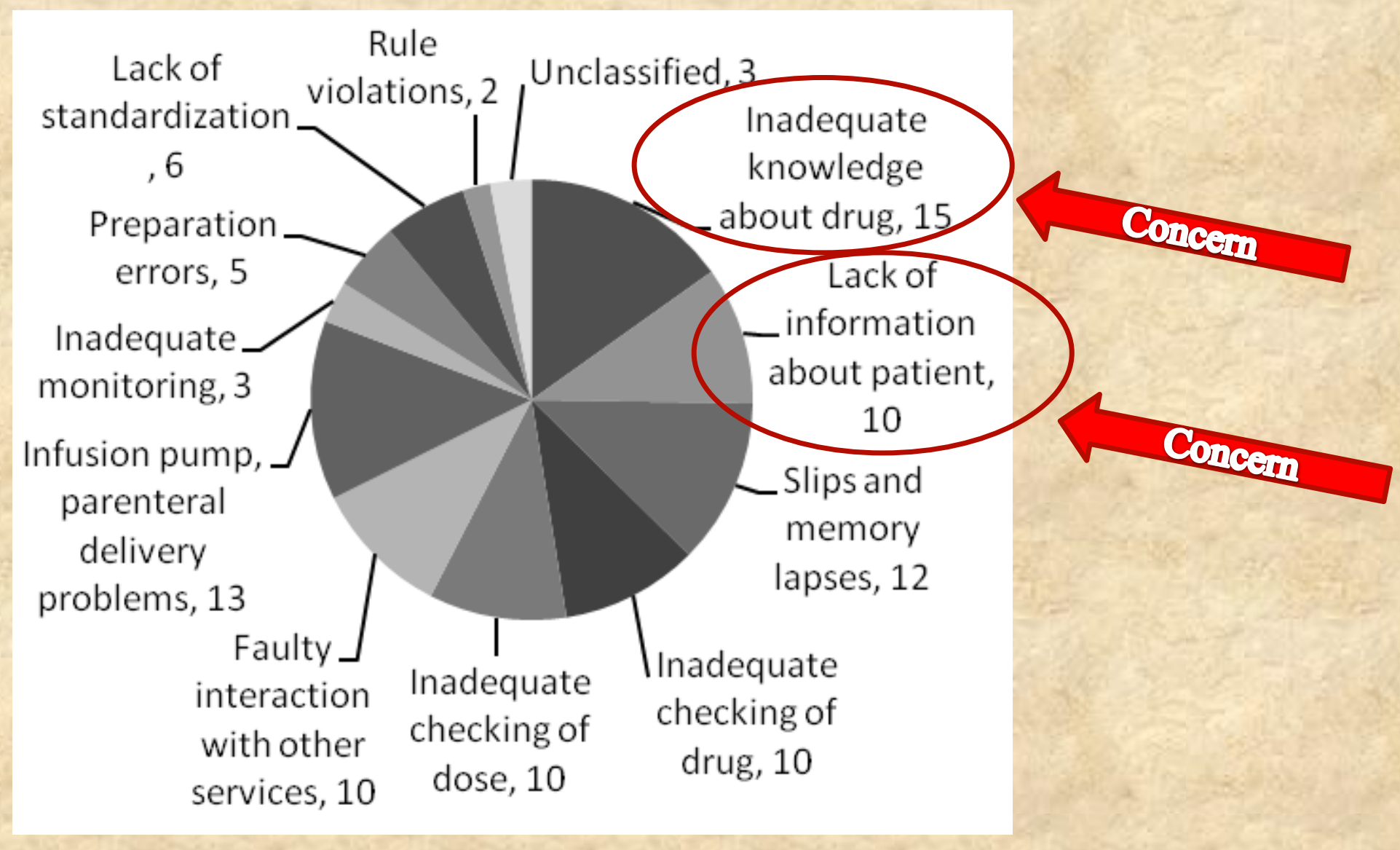




\section{STRATTON et al., 2004}

\section{Percentage of nurse respondents that chose each category as one of the two most important reasons that medication errors occur}

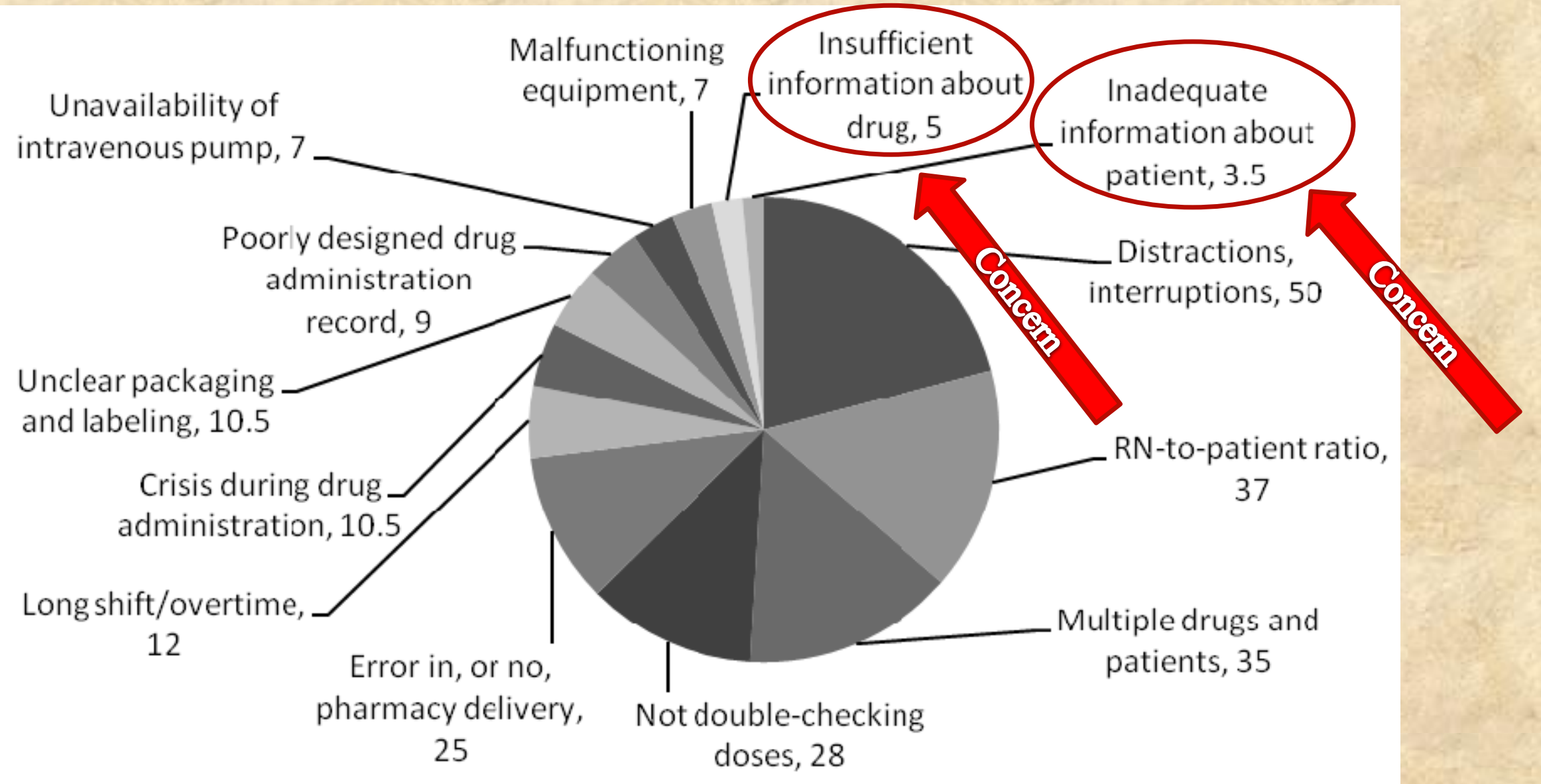




\section{IMPLICATIONS \& RECOMMEDATIONS}

* Nurses are not aware of deficiencies in their knowledge about the drug or lack of patient information

* Provide drug education, electronic drug references, and enhanced patient information to help reduce such errors 


\section{CONCLUSIONS}

* Nursing work system often does not accommodate human limitations and capabilities

* Nurses' work is cognitively demanding with frequent interruptions

* HF/E is uniquely suited to enhance nursing performance and improve patient safety

* Future research needed: Interruptions and cognitive processes in nursing 


\section{??? QUESTIONS ???}
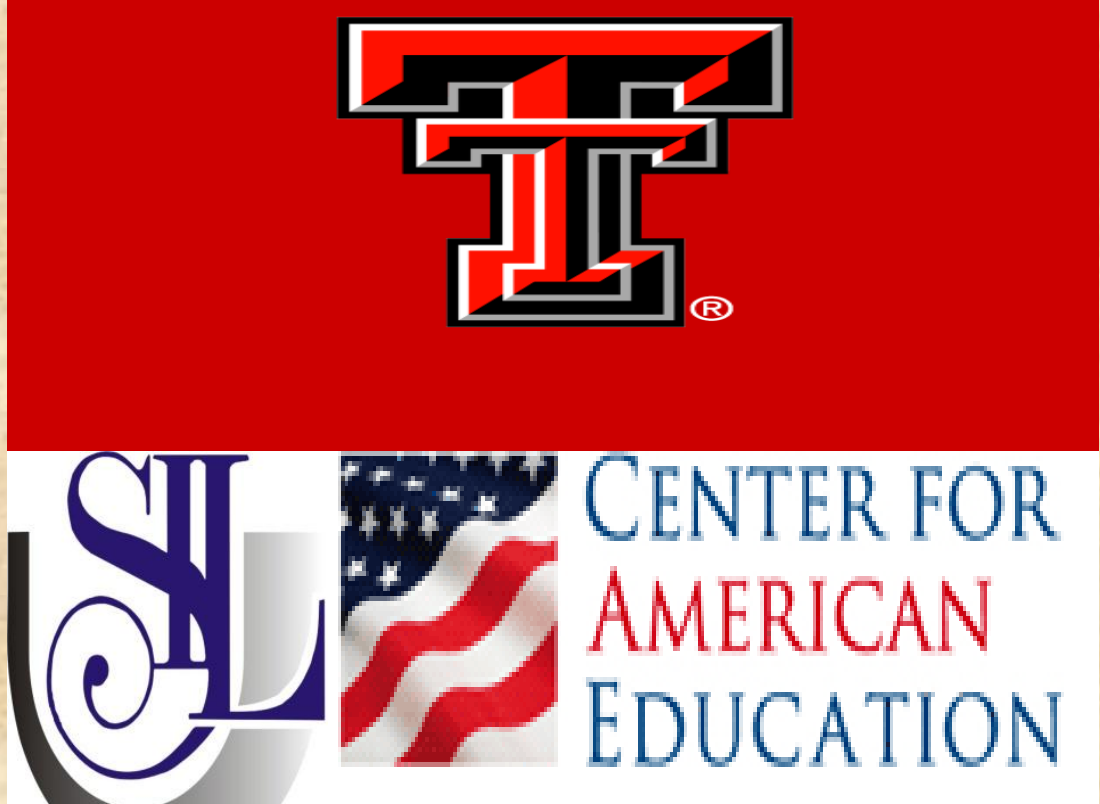

UNIVERSIDAD SAN IGNACIO DE LOYOLA

\section{THANK YOU!}

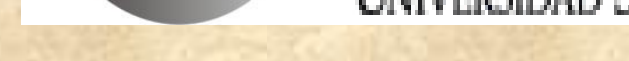


APPENDICES 


\section{Distribution of Literature Sources}

Distribution of Sources of Interruptions in Literature:

* 16 observational, field studies

* Reported interruptions of nurses

* Which sources of interruptions were identified?

* How many times was each source listed across studies? 


\section{DISTRIBUTION (by Category)}

There were 16 studies with 92 sources of interruptions listed (some more than once)

* PEOPLE (51)

* PATIENTS (16) (PLUS 34 nurse call button reasons identified in 4 studies)

* OTHER NURSES (10)

* FAMILY \& VISITORS (7)

* NON-PROFESSIONAL STAFF (9)

* EMERGENCIES (2)

* PHYSICIANS \& PHARMACISTS (7)

* ENVIRONMENT (26)

* PHONE/PAGERS (9)

ॠ NOISE (4)

* EQUIPMENT, SUPPLIES, ALARMS (8)

* MEDICATION RELATED (5)

* SELF (13)

* SELF-INTERRUPTIONS (10)

* ADMINISTRATION (3)

* ORGANIZATION (2) 


\section{LEAPE et al., 1995}

\section{Percentage of errors attributed to each category of proximal cause during nurse medication administration}

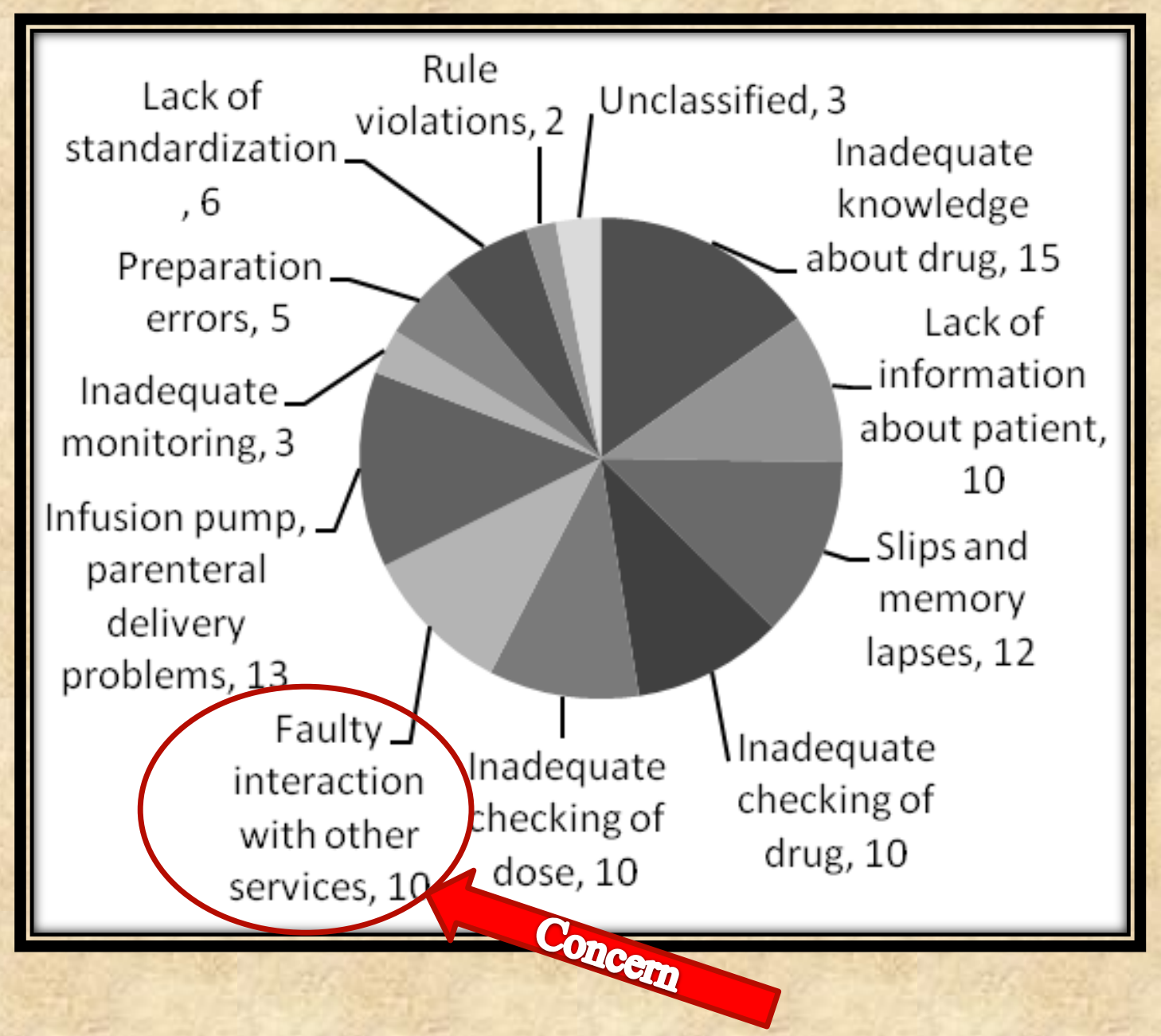




\section{EISENHAUER et al., 2007}

Percentage of times nurses reported thinking about each category during medication administration

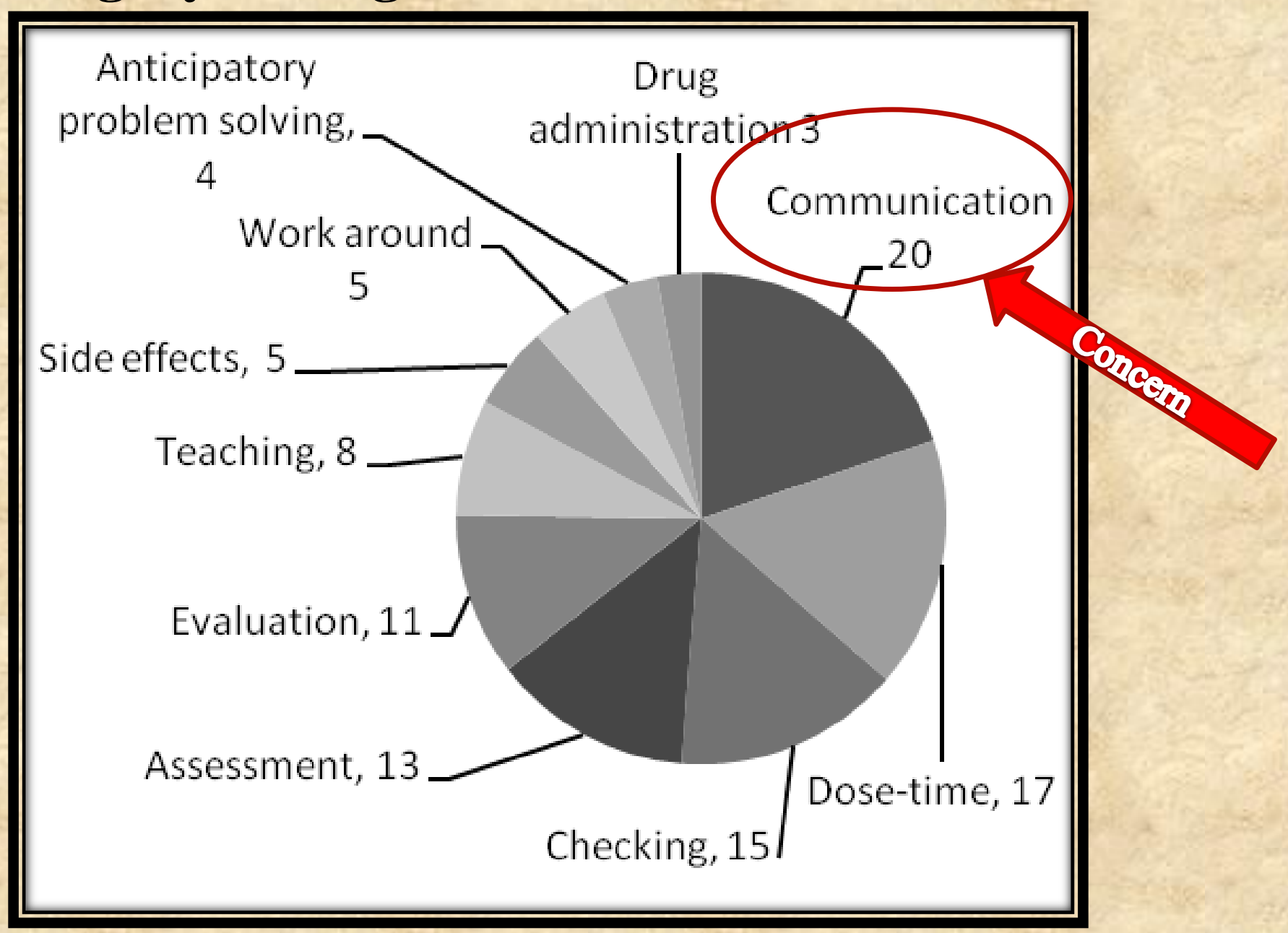




\section{OTHER IMPLICATIONS}

* Nurses are concerned about communicating information to other service departments

* Improve service coordination to help reduce this distraction 